\title{
New Cosmopolitanism as a Way out of Ethical Dilemma in Foreignization: A Comparison of Ezra Pound's and Yuanchong Xu's Classical Chinese Poetry Translation
}

\author{
Xiao Ma ${ }^{1}$, Lili Dang ${ }^{1,2, *}$ \\ ${ }^{1}$ Translation and Interpreting Department, Wuhan University, Wuhan, PR China \\ ${ }^{2}$ Translation and Interpreting Department, Northwest Normal University, Lanzhou, PR China
}

Email address:

644615343@qq.com (Lili Dang)

${ }^{*}$ Corresponding author

\section{To cite this article:}

Xiao Ma, Lili Dang. New Cosmopolitanism as a Way out of Ethical Dilemma in Foreignization: A Comparison of Ezra Pound's and Yuanchong Xu's Classical Chinese Poetry Translation. International Journal of Applied Linguistics and Translation. Vol. 6, No. 1, 2020, pp. 1-11. doi: 10.11648/j.ijalt.20200601.11

Received: January 16, 2020; Accepted: February 12, 2020; Published: February 21, 2020

\begin{abstract}
Foreignization helps to inspire investigations into the translator's invisibility, cultural hegemony in translation, and translation ethics on the one hand. On the other hand, it shows an ethical dilemma in translation that has already attracted a lot of attention throughout the world. And although existing studies have already uncovered some reasons of the ethical dilemma and put forward some solutions, the question has not been fully addressed especially when translation direction, which is an important but largely ignored factor in translation, is taken into consideration. Developments in contemporary Cosmopolitanism make new interpretation of Cosmopolitanism ethics possible and thus provide a useful theoretical tool. From a new Cosmopolitanism perspective, a Cosmopolitanism translation ethics and a strategy of negotiation, which take the self and the other in translation as equal and enable them negotiate about their difference more effectively, are then proposed to examine foreignization and ethics of difference through a comparative study of Ezra Pound's and Yuanchong Xu's classical Chinese poetry translation. The findings indicate that although foreignization morally treats the self and the other in translation as equal, it has the defect of valuing the self's values above that of the other. A new Cosmopolitanism translation ethics and a strategy of negotiation, however, can overcome the defect, therefore provide a way out of the ethical dilemma in foreignization and ethics of difference.
\end{abstract}

Keywords: Cosmopolitanism, Translation Ethics, Foreignization, Ezra Pound, Yuanchong Xu

\section{A Dilemma of Self-other Relationship in Foreignization}

In addition to inspiration, much confusion has been aroused by foreignization, or foreignizing translation, or the strategy of foreignization since its being put forward by Lawrence Venuti in The Translator's Invisibility: A History of Translation, especially when translation direction, i.e., translation from a foreign language or culture to one's native language or culture or vice versa - admit it or not, lots of translations are done from one's native language or culture to a foreign language or culture, is taken into consideration, and lots of efforts have been made throughout the world to trace the causes. In China, for example, relevant studies underwent the changes from purely focusing on the definition of foreignization to interpreting it against its cultural background, and then to integrating it with Venuti's stance on copyright and translation ethics. In the early stage, many Chinese researchers point out that foreignization tries to highlight difference in language and culture mainly by deviated and ignored forms and themes. It is not until Yameng Liu's investigation of the interaction among foreignization, domestication, ethics of difference, ethics of sameness, ethics of location, do Chinese scholars start to pay more attention to the ethical significance of foreignization and to the relationship between foreignization and copyright [1]. Jinghua Zhang, for instance, holds that the core of Venuti's translation theory lies in ethics of difference, that the 
development of foreignizing translation is also the formation of ethics of difference, that marginalization of translation is, according to Venuti, a problem of translation ethics, and that, viewed from the perspective of meta-ethics, Venuti's translation theory inevitably judges values of translation from one single ethical angle [2]. Tong Jiang points out that "foreignizing translation" and "domesticating translation" integrate discourse strategies and translation ethics into one, that "scandals of translation" is to view "foreignizing translation" and "ethics of difference" in a different way, that "minoritizing translation" aims at target culture innovation and understanding of cultural differences and paves the way for ethics of difference, that "formation of cultural identities" is to reshape cultural identities of the self and the other via foreignizing translation, and that both ethics of difference and ethics of location take target culture change and innovation as the ultimate goal of translation [3]. Reflections by other researchers upon foreignization and ethics of difference question the acceptability of the translated text and the cultural power relationships involved. As a conclusion, studies on Venuti's foreignization in China show a certain degree of "localization" in which although there is misinterpretation, the ethical tension in foreignization is partly revealed.

However, researches by scholars from other countries generally involve Venuti's stance on translation copyright and translation ethics, and the possibility of increasing the translator's visibility and fighting against cultural hegemony through foreignization is questioned. Anthony Pym, for example, holds that foreignization has not established more democratic cultural exchanges [4]. Douglas Robinson holds that foreignizing translation tries to resist fluent translation, implies elitism, and is against hegemony [5] (1997a), but may not change the reality [6] (1997b). Maria Tymoczko believes that foreignizing or resistant translation may worsen the independence and status of dominated cultures [7]. Edwin Gentzler points out that foreignizing translation is to resist domesticating translation and fight against cultural hegemony [8]. Jeremy Munday points out connection made by Venuti between translation copyright and domestication, and that between trade imbalance for translations and hegemony of British and American culture [9]. Tarek Shamma holds that foreignization can both resist and justify racism, cultural prejudices and imperialism [10]. What's more, Mary SnellHornby points out that the questioning of English hegemony by foreignization is fit for the present context of English hegemony only and can not solve all problems caused by English hegemony [11].

From all researches mentioned above, the following conclusions may be drawn: first, by laying emphasis on foreignness, foreignizing translation tries to fight against cultural hegemony and translator's invisibility, and attaches importance to translation's role in culture and history; second, the strategy of foreignization is regarded as a way to practice ethics of difference; third, the foreignness in foreignizing translation refers more to deviated forms and themes in the target culture-English culture in Venuti's case - than to foreignness of the source culture itself, and aims at innovation of the target culture; fourth, the development from ethics of difference to ethics of location reveals a much more complicated relationship among domestication, foreignization and cultural hegemony. In other words, the strategy of foreignization faces an ethical dilemma due to the dualism and utilitarianism it implies [12]. However, Venuti argues in the 2018 version of The Translator's Invisibility that he never treats foreignizing and domesticating as binary oppositions, and that foreignizing translation limits and redirects domestication inherent in translation through the effects of the linguistic and cultural resources in the target culture which are employed by the translator in foreignizing translation [13]. True as it is, opposition between the self and the other in translation is still obvious, while other possible relationship between the two, for instance, as mutual others, or interpenetration of the two, is ignored to a large extent. In addition, since Venuti attaches much importance to translation's role in innovating the target culture-the English culture in this case-foreignizing translation and ethics of difference judge ethics of translation mainly from the perspective of the cultural needs and situation of the self. In a world of inevitable globalization, the relationship between the self and the other in translation features more correlation, fusion, interpenetration, and complementation than opposition. Therefore, it is more advisable to treat the self and the other in translation as interacting with each other continuously instead of highlighting their sameness or foreignness. To judge translation ethics mainly from either side, i.e., either mainly from the side of the self or from that of the other, is to put translation into an ethical dilemma.

\section{A New Cosmopolitanism View of Self-other Relationship}

Since its coming into being, Cosmopolitanism has always involved an ethical reflection upon self-other relationship although the reflection has always been full of tensions.

\subsection{New Developments in Cosmopolitanism and Cosmopolitanism Ethics}

Cosmopolitanism can be traced back to Diogenes of ancient Greece and to Confucius of ancient China. Nowadays, globalization has brought about new developments in Cosmopolitanism and therefore in Cosmopolitanism ethics. Starting from a new global imagination in which a new world order is being and will be created out of dialogue, cooperation, competition and mutual learning across different cultures instead of being pre-existed or imposed upon by a certain power or a dominating culture, Qing Liu, a Chinese scholar, puts forward a new Cosmopolitanism by resorting to the traditional Chinese idea of Tianxia (天下), i.e., "all under heaven". According to Liu, this new Cosmopolitanism takes universalism as a transcultural construction into which local universalism originating from different regions converge through mutual 
learning and dialogues, and which is restricted at the same time by local particularities. Liu holds that He'er Butong (和 而不同), i.e., “to seek harmony in diversity" included in the idea of "all under heaven" enables different cultures to interact with each other in a way of mutual respect, equal dialogue and peaceful competition, a New Huayi Zhibian (新 华夷之辨), i.e., “to distinguish different communities according to different cultural concepts independent of a certain geographical location or race" which is a new development of Huayi Zhibian (“华夷之辨”), i.e., “to distinguish Han from minority nationalities according to their differences in national identity" in the traditional idea of "all under heaven" helps to overcome the binary opposition between national states and a world order, and Qiutong Cunyi (求同存异), i.e., “to seek common ground while reserving differences" which is also included in the idea of "all under heaven" means to make every effort to construct universalism out of the similarities and dissimilarities between the self and the other and to maintain an open attitude towards fundamental differences [14].

Cosmopolitanism ethics is mainly about the morality definition and value judgment of self-other relationship in various fields in accordance with Cosmopolitanism [15]. What's more, individualism and universalism constitute the philosophical bases of Cosmopolitanism ethics [16], while the core propositions of Cosmopolitanism ethics lie in that both the individual and the whole human being are considered as basic value goals and ultimate units of moral concern, with each individual enjoying equal moral status and value order, and that all individuals are regarded as world citizens, and thus there exists a priori connection between individuals as world citizens [15].

Based on the above-mentioned viewpoints, a new Cosmopolitanism ethics becomes possible: self-other relationship, at either the individual level or the cultural community level, involves a process of construction in which the two, each as the self and the other at the same time, interacts with each other continuously; since the self and the other are morally equal, their particularities too should be treated as equal and should not be universalized; besides, both as world citizens or as cultural communities sharing the same world, the self and the other is connected to each other, and this kind of connection can be further explored and cultivated so as to build a solid foundation for the two sides to reflect upon and negotiate over their difference in value pursuit with an aim of mutual learning and development; what's more, when moral concern and value pursuit conflict with each other and cause a dilemma, for instance, even though both the two sides morally treat each other as equals, their differences in politics, economy, etc., may allow no agreement on their value pursuits, it is crucial then not to try to eliminate those differences at once and not to regard those differences as something eternal.

\subsection{A New Cosmopolitanism Translation Ethics and a Translation Strategy of Negotiation}

Researchers differ from each other in their definitions of translation ethics. Wei Fang, a Chinese scholar, by resorting to contemporary developments in moral philosophy and virtue ethics, puts forward, as a criticism of "norms-oriented" translation ethics, that "Broadly, translation ethics is about how participants in translation treat the relationship between freedom and order and take actions", and holds that translation ethics studies should shift their focus from norms to virtues or values which constitute the basis for norms [17].

Inspired by the new developments in Cosmopolitanism and Cosmopolitanism ethics and Wei Fang's emphasis on virtues or values in translation ethics, we propose a Cosmopolitanism translation ethics according to which participants in translation treat from the perspective of moral concern the self and the other, each as the other's other, as equals, and examine from the perspective of value subject differences in value pursuits between the self and the other on the basis of the connection between the two sides, both as world citizens or as communities sharing the same world, and face and take actions to deal with the dilemma caused by conflicts between the two perspectives.

To be more specific, guided by a Cosmopolitanism translation ethics, the participants in translation such as the author, the translator, the patron, and the reader, etc., who actually fulfill the roles of the self and the other in translation at both the individual level and the cultural community level, need to morally regard each other as mutual others and respect each other's cultural particularities rather than replace the other's standard with the self's standard. And the natural connection between participants in translation, i.e., the self and the other in translation, who are all world citizens or share the same world, can be further explored and cultivated so as to build a solid foundation for the two sides to negotiate over their differences to reach mutual learning and progress. It can not be denied that, nevertheless, since there does exists enormous imbalance between different cultures, it is inevitable that different value orientations may conflict with the demand for equality, therefore, it is crucial to emphasize an open attitude towards these conflicts by treating them as changeable together with historical and cultural contexts.

Generally, translation ethics is realized through employment of a certain translation strategy. In the case of the Cosmopolitanism translation ethics proposed above, it is necessary to adopt a translation strategy of cultural negotiation, that is to say, questions like what texts to be translated or what translation methods to be used are decided by the results of negotiation between participants in translation over differences between two cultures on the basis of similarities or common needs of the two cultures so as to promote equal and mutual beneficial cultural exchanges via translation.

\section{A Comparison of Ezra Pound's and Yuanchong Xu's Translation of Classical Chinese Poetry}

Compared with foreignizing translation and ethics of 
difference that focus more on differences between the self and the other in translation and thus may result in an ethical dilemma, the strategy of negotiation and the Cosmopolitanism translation ethics are concerned to focus not only on differences between the self and the other in translation, but also on connection, interpenetration, complementation between the two sides, and on the fact that the self and the other are mutual others, i.e., both the self and the other in translation play a dual role, which therefore may enable us to get out of the dilemma foreignizing translation and ethics of difference bring about. As an illustration, the following is a comparison between the translation of classical Chinese poetry by Ezra Pound, which is done from the foreign language or culture into the native language or culture, and that by Yuanchong $\mathrm{Xu}$, which is done from the native language or culture into the foreign language or culture.

Before actually going on with the comparison, it is necessary to note that in 2018 version of The Translator's Invisibility, Venuti explains that domesticating and foreignizing describe "the ethical effects of translated texts that depend for their force and recognition on the receiving culture" instead of "specific verbal choices or discursive strategies used in translation" and infers that discursive strategies have no necessary ethical value, that foreignizing translation does not necessarily means literalism or close adherence to the source text but an approach that aims to "interpret the source text against dominant forms, practices, traditions, and interpretations in the receiving situation", which means a foreignizing effect can be produced through a "choice of a source text" or "innovative strategies" and varies according to text types, and that fluency dominates translation throughout the world [13]. It's true that translation strategies can not be identified with intrinsic ethical effects without taking their cultural and historical contexts into consideration. However, there is self-centeredness in the explanation because all ethical judgments are made principally from the standards of the target culture that regards itself as the self and the source culture as the other instead of regarding the self and the other in translation as mutual others. Besides, even though there is no necessary identification between a translation strategy and an ethical effect, it is still important to investigate into the relationship between the two within a certain cultural and historical context. Or else, it can be declared that all translation is foreignizing because no translation can totally get rid of foreignness in its source text whether it is read as translation or not, or whether the translator is visible or not. The following discussion, therefore, still try to analyze the translation strategies through the choice of source texts and the translation methods within their cultural and historical contexts so as to find out their ethical bases.

Concerning the selection of translations to be compared, Yuanchong Xu's translation has covered the whole history of classical Chinese poetry ranging from Book of Poetry (《诗 经》), Elegies of the South (《楚辞》), Golden Treasure of Chinese Poetry in Han, Wei and Six Dynasties (《汉魏六朝
诗选》), 300 Tang Poems (《唐诗三百首》), Selected Lyrics of Tang and Five Dynasties (《唐五代词选》), 300 Song Lyrics (《宋词 300 首》), Selected Pomes of Li Bai (《李白诗选》), Selected Pomes of Du Fu (《杜甫诗选》), Poems of Su Shi (《苏轼诗词》), to Golden Treasure of Song, Yuan, Ming and Qing Dynasty Poetry (《宋元明清诗 选》), while Pound's most famous classical Chinese poetry translations are collected mainly in Cathay, besides, it is also necessary to take typical features of the original poems into consideration, therefore, the two translators' versions of the following poems, i.e., Cai Wei (《采薇》), Qingqing Hepancao (《青青河畔草》), Changgan Xing (《长干 行》), Yujie Yuan (《玉阶怨》), Weicheng Qu/Song Yuan'er Shi Anxi (《渭城曲/送元二使安西》), Huanghelou Song Menghaoran Zhi Guangling (《黄鹤楼送孟浩然之广陵》), Song Youren (《送友人》), Deng Jinling Fenghuangtai (《登金陵凤凰台》), are taken as comparable samples [18].

\subsection{A Description of Pound's and Xu's Treatment of Classical Chinese Poetry}

Since poetry generally integrate sounds, forms and meanings into wholes, and even Pound's comments on melopoeia, phanopoeia and logopoeia [19] imply that poetry in different languages combine the three features in different proportions [20], the following analysis will pay attention to all the three features. As a matter of fact, to treat classical Chinese poetry as typical phanopoeia that underscores indestructible images or visuality of pomes is to largely ignore the beauty in sound and in line arrangements of classical Chinese poetry which are also essential.

Among the samples, the original of Wang Wei's (王维) Weicheng $Q u$ (《渭城曲》), also called Song Yuan'er Shi Anxi (《送元二使安西》), of which Pound's translation is collected in Cathay as one of the "Four Poems of Departure", reads as follows:

渭城曲/送元二使安西

王维

渭城朝雨淏轻尘,

客舍青青柳色新。

劝君更尽一杯酒,

西出阳关无故人。

And Pound's translation is as follows:

Four Poems of Departure

By Rihaku or Omakitsu

Light rain is on the light dust.

The willows of the inn-yard

Will be going greener and greener,

But you, Sir, had better take wine ere your departure;

For you will have no friends about you

When you come to the Gate of Go. [21]

And Xu's version goes:

A Farewell Song

Wang Wei

No dust is raised on pathways wet with morning rain,

The willows by the tavern look so fresh and green.

I invite you to drink a cup of wine again,

West of the Southern Pass no more friends will be seen. 
[22]

In Chinese poetics, the principle of "poetry express ideas and emotions (诗言志)" has always taken a dominant role. The beauty in sense, i.e., in ideas and emotions, of a poem thus is regarded as the spirit of the poem. In the case of Weicheng Qu/Song Yuan'er Shi Anxi, it is the friendship felt between two parting friends that constitute the poem's spirit. Specifically, the first two lines introduce the place, time and scenery of the parting. It is in the morning, and the rain wets the dust on the pathways. The willow (柳, sounds like 留 which means not to leave) by the inn of the town Weicheng (渭城), which refers to the town in the north of Weishui (渭 水, Wei River), looks fresher and greener because of the rain. It seems that it is the wrong time for friends to part. The last two lines, however, only chooses one shot of the farewell to depict: the poet invites the friend to drink one more cup of wine by asserting that there may be no old friend to turn for companionship once west out of Yangguan (阳关) which is the last pass leading to the western regions that were still desolate at that time. Without mentioning sorrow directly, the feeling of sorrow deepens along with the progression of the poem.

Despite of the fact that Pound's treatment omits “Weicheng” (渭城) and understates “Yangguan” (阳关) as "gates of Go", which loses its original reference, the treatment transmits the sorrow of separation between friends well especially in the last three lines since Pound's translation often tries to bring over the "indestructible" "human emotion" of the original [23].

Similarly, in Xu's version, “Weicheng” (渭城) is absent and "Yangguan" (阳关) only becomes "the Southern Pass" because "It's necessary to flexibly deal with proper nouns of which literal translation can not serve to bring over the beauty in sense of the original" [24]. While the sorrow of separation between friends is conveyed clearly in Xu's last two lines.

As a matter of fact, both Pound and Xu also transmit well the sorrow/reluctance of separation between friends in Huanghelou Song Menghaoran Zhi Guangling ( 《黄鹤楼送 孟浩然之广陵》), Song Youren (《送友人》), the estrangement of a deserted wife/court lady in Qingqing Hepancao (《青青河畔草》), Changgan Xing (《长干 行》), Yujie Yuan (《玉阶怨》), the sorrow of war in Cai Wei (《采薇》), and the vicissitude and sadness in Deng Jinling Fenghuangtai (《登金陵凤凰台》).

However, the musicality or beauty in sound is also a typical and undeniable feature of classical Chinese poetry, and Weicheng Qu/Song Yuan'er Shi Anxi is no exception. The first, second and fourth lines rhymes with each other at the end with the sounds "en" and "in" (" $R$ " in the following illustration), each line can be read in the two-two-three pattern of rhythmic units, i.e., two or three Chinese characters constituting a rhythmic unit (“/”), and the lines also have its own tone pattern regularly changing between a Level Tone (“-") and a Defected Tone ("+"). Here is an illustration.

$$
+-/-+/+--(\mathrm{R})
$$

$$
\begin{aligned}
& ++/--/++-(\mathrm{R}) \\
& +-/++/+-+ \\
& -+/--/-+-(\mathrm{R})[18]
\end{aligned}
$$

Pound's lines are mainly made up of two or three phrases in spondee, and together with changes in moods, there is changes in rhythm within a line. The fourth line, for instance, consists of four phrases but still in spondee. In addition, "light" in the first line repeats, "willow" in the second line and "will" in the third line form alliteration, "greener" in the third line repeats and rhymes with "sir, better, ere, departure" in the fourth line, "you" in the fifth line rhymes with "Go" in the sixth line, and "Gate" and "Go" in the sixth line are in alliteration. Pound's translation is in a rhythm that "closely corresponds to the poet's emotions" and largely ignores the musicality of the original [25].

Comparatively, by rendering the original end rhyme of "en" and "in" into rhyme of "[ei]" and "[i:]" at the end of every one line, and the original fixed tone pattern and the rhythmic unit pattern into six feet iambic meter, $\mathrm{Xu}$ is trying to achieve in his translation resemblance in sound to the original because beauty in sound is an essential feature of classical Chinese poetry that deserves to be introduced to the world culture.

In fact, both $\mathrm{Xu}$ and Pound stick to their own way of treating the musicality of classical Chinese poetry. In addition to the end rhyme, the fixed rhythmic units, and the tone pattern, other typical sound effects of classical Chinese poetry are largely ignored by Pound while transmitted by $\mathrm{Xu}$ as much as possible. To take Cai Wei (《采薇》), which repeats whole phrases and stanzas with a few words changed to produce a melodious effect of a folk song that may be sung or played when set to music, and Qingqing Hepancao (《青 青河畔草》), whose reduplicated characters (叠音词) attributes much to the lively rhythm of the poem, as more examples:

The first three stanzas of Cai Wei (《采薇》) reads:

采薇

先秦・佚名

采薇采薇,

薇亦作止。

曰归曰归,

岁亦莫止。

靡室靡家,

猃狁之故。

不遑启居,

猃狁之故。

采薇采薇,

薇亦柔止。

曰归曰归,

心亦忧止。

忧心烈烈,

载饥载渴。

我戍未定,

靡使归聘。

采薇采薇, 
微亦刚止。

曰归曰归,

岁亦阳止。

王事靡監,

不遑启处。

忧心孔疚,

我行不来。

Pound's translation goes:

Song of the Bowmen of Shu

By Bunno, reputedly 1100 B. C.

Here we are, picking the first fern-shoots

And saying: When shall we get back to our country?

Here we are because we have the Ken-nin for our foemen,

We have no comfort because of these Mongols.

We grub the soft fern-shoots,

When anyone says "Return," the others are full of sorrow.

Sorrowful minds, sorrow is strong, we are hungry and thirsty.

Our defence is not yet made sure, no one can let his friend return.

We grub the old fern-stalks.

We say: Will we be let to go back in October?

There is no ease in royal affairs, we have no comfort.

Our sorrow is bitter, but we would not return to our country. [21]

Xu's translation goes:

A Homesick Warrior

Anonymous

We gather fern

Which springs up here.

Why not return

Now ends the year?

We left dear ones

To fight the Huns.

We wake all night.

The Huns cause fright.

We gather fern

So tender here.

Why not return?

My heart feels drear

Hard pressed by thirst

And hunger worst,

My heart is burning

For home I'm yearning.

Far from home, how

To send word now?

We gather fern

Which grow tough here.

Why not return?

The tenth month's near.

The war not won,

We cannot rest.

Consoled by none,

We feel distressed. [26]

Compared with that of Pound, Xu's version tries to bring over the repetition of the original by repeating the first four lines with only a few words in them changed since $\mathrm{Xu}$ believes that "beauty in sound" must be preserved in translations of classical Chinese poetry. In contrast, Pound's version runs "in the sequence of the musical phrase" [19] instead of approximating the repetition of phrases in the original.

And reduplicated characters (叠音词) in Qingqing Hepancao (《青青河畔草》) are dealt with by Pound and $\mathrm{Xu}$ in their translations as follows:

The original reads:

青青河畔草

佚名

青青河畔草,

郁郁园中柳。

盈盈楼上女,

皎皎当窗牑。

娥娥红粉妆,

纤纤出素手。

昔为倡家女,

今为荡子妇。

荡子行不归,

空床难独守。

Pound's version reads:

The Beautiful Toilet

By Mei Sheng, 140 B. C.

Blue, blue is the grass about the river

And the willows have overfilled the close garden.

And within, the mistress, in the midmost of her youth,

White, white of face, hesitates, passing the door.

Slender, she puts forth a slender hand:

And she was a courtesan in the old days,

And she has married a sot,

Who now goes drunkenly out

And leaves her too much alone. [21]

And Xu's version reads:

Green, Green Riverside Grass

Anonymous

Green, green riverside grass she sees;

Lush, lush the garden's willow trees.

Fair, fair, she waits in painted bower,

Bright, bright like a window-framed flower.

In rosy, rosy dress she stands;

She puts forth slender, slender hands.

A singing girl in early life,

Now she is a deserted wife.

Her husband's gone far, far, away.

How to keep lonely bed each day! [27]

“青青，郁郁，盈盈，皎皎，娥娥，纤纤” enables the original to sound melodious and lively. Pound waves the reduplications into the lines by reduplicating "blue", "white", "slender" in the first, fourth and sixth lines respectively - the fifth line is taken by Pound as the title of his translation, and by pairing and clustering "willowed, overfilled; within, mistress, midmost" in the second and third lines [28]. And by so doing, "Pound has kept intact the natural breath of the English language" [23]. Comparatively, by reduplicating 
“green", "lush", “fair", "bright”, “rosy”, “slender", Xu aims to achieve resemblance in sound in his translation.

Besides, the beauty in form of classical Chinese poetry is largely related to dense images, and "the logical relations between images are ambiguous since images are directly juxtaposed against each other without any linking words" [29]. In Weicheng Qu/Song Yuan'er Shi Anxi, "Weicheng, the morning rain, the dust, the inn, the willow, the wine, Yangguan, old friends" all constitute images inspiring certain emotions.

Despite of the insertion of linking words like "is", Pound's version presents in detail through "light rain, light dust, willows, inn-yard, going greener, take wine, friends" the images of the scene of parting between two friends vividly while at the same time loses the images of "Weicheng, Yangguan" which are also typical images of the separation. $\mathrm{Xu}$ 's treatments too loses the images of "Weicheng, Yangguan" but keeps the images of the original by using "dust, pathway, wet, morning rain, willows, tavern, fresh and green, invite, a cup of wine, friends".

Antitheses are often used to combine images of different time and space to get reader to be ready to accept leaps between images as natural transitions [29]. Besides, antithetical words and phrases should be of the same part of speech or refer to things of the same category. Taking the antithesis in Song Youren (《送友人》) as an example:

The original antithesis in Song Youren (《送友人》) goes: 浮云游子意,

落日故人情。

Pound's treatment goes:

Mind like a floating wide cloud,

Sunset like the parting of old acquaintances. [21]

Xu's treatment goes:

Like floating cloud you'll float away,

With parting day I'll part from you. [22]

In the original, the juxtaposition of “浮云”/floating clouds with “游子意”/wanderer's thought, “落日”/setting sun with “故人情”/old friend's feeling without any connectives already creates vivid images, while the antithesis between the two lines, i.e., “浮云”/floating clouds against “落日”/setting sun, “游子意”/wanderer's thought against “故人情”/old friend's feeling, psychologically prepares readers for the transition between images of different time and space.

Although Pound's introduction of "like" destroys the syntactically uncommitted resemblance in the original juxtaposition, "an abstract idea is placed against a concrete image" [23]. The original antithesis, however, is almost totally lost. In contrast, in Xu's treatment, images of “游子 意”/wanderer's thought, “落日”/setting sun, “故人情”/old friend's feeling are largely ignored, while the form of an antithesis is kept with "like" against "with", "floating cloud" against "parting day", "you'll float away" against "I'll part from you".

In fact, the antitheses in Deng Jinling Fenghuangtai (《登 金陵凤凰台》) go through the same treatment in Pound's and Xu's translations respectively.

The original reads:

吴宫花草埋幽径,
晋代衣冠成古丘。

三山半落青天外,

二水中分白鹭洲。

Pound's version reads:

Flowers and grass.

Cover over the dark path

where lay the dynastic house of the Go.

The bright cloths and bright caps of Shin

Are now the base of old hills.

The three Mountains fall through the far heaven,

The isle of White Heron

splits the two streams apart.[21]

$\mathrm{Xu}$ 's treatment is:

The ruined palace's buried'neath the weeds in spring;

The ancient sags in caps and gowns all lie in graves.

The three-peak's mountain is half lost in azure sky;

The two-fork'd stream by Egret Isle is kept apart. [30]

In the first antithesis of the original, “吴宫”/ Wu palace is against “晋代”/ Jin Dynasty, “花草”/ flower and grass against “衣冠”/ sags and caps, “埋”/ to bury against “成”/ to become, “幽径”/ secluded path against “古丘” / old hills; in the second antithesis, “三山”/ Three-peaked Mountain is against “二水”/ two-forked river, “半落”/ almost lost against “中分”/ separated apart, “青天外”/ far sky against “白路洲” / Egret Isle. Obviously, nouns are in contrast with nouns, and verbs are in contrast with verbs. Besides, through the antithesis, images of different time and space are combined together.

In Pound's version, the lines are broken into different shots and thus the images attain greater visuality, and the original four lines are spaced out as two parts that play against each other to emphasize the irony [23]. The original antitheses are therefore completely ignored. In Xu's version, however, despite of the inversion of the word order out the need of rhyme, efforts are made to transmit the original antitheses partly by contrasting "the ruined palace" with "the ancient sags", "the three-peak's mountain" with " the two-fork'd stream".

Weicheng Qu/Song Yuan'er Shi Anxi also shows a beauty in form resulting from the interplay of irony and the fixed length of lines. The interplay between the refreshing scenery in first two lines and the parting between friends in the last two lines is obvious and highlights the sorrow of separation. Regarding the line length, the original is a seven-character poem of modern style (七言近体诗) of whom each line has seven characters.

In Pound's translation, the turn taken by the last three lines-"But you, Sir, had better take wine ere your departure,..." shows a similar interplay of irony in the original. Pound even dramatizes the interplay of irony in his translation of Qingqing Hepancao (《青青河畔草》) mentioned above in a way which "spaces out the last four lines, allowing the second impression to play against the one captured in the previous five lines and the title [23]. And this kind of graphic device is widely used in Pound's Imagist poems to "stress an unprepared shift, either to a plane of 
sense experience entirely different from what goes before it or to a strong contrast" [23]. Xu's translation often approximates the original in this aspect.

The fixed line length of Weicheng Qu/Song Yuan'er Shi Anxi, actually of all originals whose translations are collected in Cathay, which is a basic requirement of classical Chinese poems, is totally ignored by Pound. The lines of a classical Chinese poem often share a fixed length either of four characters or five characters or seven characters and thus create a beauty in form. In Pound's version, however, the lines are usually in irregular length, while Xu's version often tries to bring over the line length by translating sevencharacter lines into twelve-syllabic lines, Weicheng Qu/Song Yuan'er Shi Anxi (《渭城曲/送元二使安西》) and Deng Jinling Fenghuangtai (《登金陵凤凰台》) for instance, four-character lines into four-syllabic lines, Cai Wei (《采 薇》) for example, and five-character lines into eightsyllabic lines, Qingqing Hepancao (《青青河畔草》) for example.

From the description above, it can be drawn that Pound mainly tries to transmit the indestructible human emotions and sharp images of classical Chinese poetry, which he takes as typical "phanopoeia" [19], through exact details, juxtaposed images and spacing out lines as well as musical phrases that corresponding to the emotions expressed while ignoring the musicality and line arrangements of the original, while $\mathrm{Xu}$ makes efforts to introduce in his translation the beauty in three aspects of classical Chinese poetry to the world by approximating the original musicality and line arrangements together with emphasis on the transmission of the emotions. As a matter of fact, Xu holds that translation of classical Chinese poetry "needs to achieve beauty in three aspects at the same time as much as possible", and in case of any conflict between beauty in three aspects, "the translator may first give up resemblance in form, then resemblance in sound, but no matter how difficult it is, beauty in sense and sound must be kept in translated versions" [24].

\subsection{A Discussion of Pound's and Xu's Translation Strategies and Their Ethical Basis}

Pound's translation is closely related to Venuti's foreignizing translation. Yet Venuti's discussion centers on Pound's translation of Guido Cavalcanti rather than on that of classical Chinese poetry, Cathay, which Pound considers as new poems, and for which Pound is well-known worldwide. And as a conclusion, Venuti holds that due to Pound's "reliance on preexisting forms", both his interpretative translations and translations that are new poems can be traced back to "the innovations of modernist poetics", and so both offer the side of the foreign text that is "selected and framed by Anglophone modernism." [13] Convincing as it is, it is not the whole story.

Pound's Cathay was published in 1915, when English culture or western culture in general, which in Pound's case plays the role of the self, was still in the shadow of the First World War, and when innovations in English poetry that was still Victorian were put on the agenda, and Imagism, as one of the most influential branch in the American New Poetry Movement started already-before the end of the year 1913 when Pound got Ernest Fenollosa's notes, "A Few Don'ts" (March, 1913), In a Station of the Metro (April, 1913), Des Imagistes (before the end of 1913) were all published, and "the three principles" (March, 1913) was listed [31]. Besides, orientalism and Chinoiserie had been influential since the 19th century, and The She King or The Book of Ancient Poetry translated by James Legge (1876) and Chinese Poetry in English Verse translated by Herbert Allen Giles (1898) had been published. While concerning the Chinese culture at that time, which plays the role of the other in Pound's translation, although the Republic of China was just founded, after years of colonization and civil wars, the Chinese society at that time had been suffering two much, doubts about its own culture and desires for learning from advanced western culture were ever increasing. Classical Chinese poetry lost its centuries-old dominance in Chinese literature to rapid developments of novels. Large scale of translation of western novels, English novels in particular, was done as an effective way to learn from western culture.

Against the above-mentioned cultural and historical context, Pound's treatment of classical Chinese poetry naturally involves a practice of his Imagist poetics so as to serve the agenda of English poetry innovation. And since it's from a foreign language or culture into his native language or culture that Pound translates classical Chinese poetry, the translation is to practice the self's poetics by translating the other in order to serve the purpose of innovation in the self. Besides, since Imagism was still experimental and marginal in the English poetry world at that time, Pound translates classical Chinese poetry in accordance with his Imagist poetics is to highlight the other's foreignness that is "selected and framed by Anglophone modernism." [13] by resorting to the self's non-mainstream forms. In addition, regarded as brilliant poems of Imagism, the translations in Cathay helps to promote the New Poetry Movement and introduce some features of classical Chinese poetry to English world. Therefore, Pound's translation of classical Chinese poetry is foreignizing in the sense that it highlights certain foreignness of the other's poetics through resorting to the self's marginal poetics and helps to innovate the self's poetics.

A new Cosmopolitanism translation ethics and a translation strategy of negotiation, however, help to reveal another aspect of Pound's translation. Taking the interaction between the target English culture that constitutes the self and the source Chinese culture that constitutes the other in Pound's translation into consideration, as a critic of the self culture and a leader of Imagism, Pound sees in the culture and poetics of the other all that is in agreement with or may promote Imagism. Pound thus treats the self and the other in his translation as equal and focuses on the common aspects between the two. Or it may be drawn that, instead of being foreignizing and showing an ethics of difference, Pound's translation of classical Chinese poetry shows an emphasis on the similarities and equality between the self and the 
other, which is Cosmopolitanism to a certain degree.

And a new Cosmopolitanism translation ethics and a translation strategy of negotiation also enable us to look from the other's point of view. In Pound's translation, classical Chinese poetry represents the other culture, i.e., Chinese culture. It is widely acknowledged that classical Chinese poetry show beauty in three aspects (三美说), i.e., in form, sound and sense（形美，音美，意美）, and beauty in form often results from antitheses, line length and images, beauty in sound often results from reduplicated characters, tone patterns, end rhyme, patterns of rhythmic unit, repetition, and beauty in sense often results from ideas or emotions in the poems and also images [29]. Among beauty in three aspects, that in sense is the most important, then comes that in sound, then that in form, but good classical Chinese poetry need to integrate beauty in three aspects into one. Pound's versions obviously deviate from original versions a lot although both of them attach much importance to images or juxtaposition of images, and Pound's assertion that classical Chinese poetry is typical "phanopoeia" covers only an important but small part of the facts. Was it some insurmountable difficulties that prevented Pound from learning more about classical Chinese poetry? At least James Legge's and Herbert Allen Giles's translations of classical Chinese poetry which were published one or several decades ago can provide some help. It is then more sensible to say that Pound deliberately understands classical Chinese poetry in an Imagist way which means a conscious choice of certain features of the other culture that is obviously a dominated culture at that time out of the needs of the self culture.

As a conclusion, to view Pound's classical Chinese poetry translation from a perspective of a new Cosmopolitanism ethics and a strategy of negotiation, it can be found out that Pound morally treats the self and the other in his case as equal by emphasizing similarities between the two on the one hand, on the other hand, his conscious choice of the other culture out of the needs of the self culture largely ignores other important features of the other culture and thus largely replace the other's value pursuit with that of the self. Therefore, it can be drawn that although foreignization and ethics of difference treat the self and the other in translation equally in a moral sense, they can not effectively reveal and deal with the tension in value pursuits of the two sides, while a new Cosmopolitanism translation ethics and a strategy of negotiation may help in this aspect by looking at translation from both sides of the self and the other and taking both moral equality and actual value pursuits in translation into consideration.

As a contrast, since $\mathrm{Xu}$ translates from his native language or culture, i.e. Chinese culture, to a foreign language or culture, i.e., English culture, it is to translate the self culture into the other culture, which clearly reveals the fact that the self and the other in translation are mutual others. And most of Xu's translation of classical Chinese poetry was done after 1980 when China has come into an era of reform and opening-up. China has ever since been developing its economy through learning from western experience on the one hand, on the other hand, despite of all kinds of achievements in literature and other cultural fields, Chinese culture is still facing a world dominated by English culture, particularly by American culture, and only a limited part of Chinese literature is translated into English culture. Both the government of China and Chinese scholars then realize the necessity of introducing Chinese literature and other cultural achievements in China into English culture so as to be better understood and to contribute to the world culture. While English culture, American culture in particular, leads the trend in many fields, and since 1945, in addition to a rapid development of postmodern fictions, American literature also witnesses a development of postmodern poetry which stresses process, aims at common people, portrays daily life, is in open form, autobiographic, colloquial, meditative, and individualized [32]. In this kind of cultural context, Xu's translation mainly aims to introduce classical Chinese poetry that is among the most brilliant achievements in Chinese literature into English culture, to put it in Xu's own words, "On the one hand, it is necessary to introduce foreign cultures into Chinese culture, on the other hand, it is necessary to introduce Chinese culture to the world culture" [24] so that a more rich and colorful world culture may be achieved.

Xu's translation, therefore, basically tries to bring over as much as possible the unique features of the self culture that deserves to be introduced to the world culture in his belief. And since Xu's translation that attaches great importance not only to the emotions, images and interplay of irony, but to end rhymes, regular meters, repetition of stanzas, antitheses, line length, deviate from the mainstream of the English poetry, it is also foreignizing and shows a certain degree of ethics of difference.

But when judged from the viewpoint of a new Cosmopolitanism translation ethics and a translation strategy of negotiation, Xu tries to stick to "beauty in three aspects" in his translation is to translate the self into the other so as to enrich the other's culture then the world culture as a whole, he then does not treat the self-other relationship in his case as something dominated-dominating but as equal, which no doubt shows a tendency of Cosmopolitanism.

What's more, it is also necessary to look at the other's stance in Xu's case according to a new Cosmopolitanism translation ethics and a translation strategy of negotiation. English culture is obviously a dominating culture in Xu's translation, and postmodern poetry does develop and be influential after two world wars in English literature. In such circumstances, sticking to "beauty in three aspects" of the self culture tends to make a requirement for the other culture in accordance with the standard of the self culture and may suffer from resistance from the other culture.

On the whole, viewed from the perspective of a new Cosmopolitanism ethics and a strategy of negotiation, $\mathrm{Xu}$ maintains confidence in the self culture and believes the uniqueness of the self culture may attribute to enrichment of the other culture in spite of the dominance of the other culture, he thus morally treats the self and the other in his 
case equally. Meanwhile, due to an ignorance of the current situation of the other culture, Xu's translation does not enable an effective negotiation between the two cultures and tends also to replace the other's value pursuit with that of the self. Once again, despite of the equality in a moral sense, there is a conflict between value pursuits of the two sides. To be more specific, if Pound's case shows a purposeful selection of the other culture out of the needs of the self culture, Xu's case shows an imposition of the self culture's value standard upon that of the other culture. Xu's translations, as a result, are mainly read and highly spoken of by Chinese readers who have learned English, but can only regarded as something between "very good" and "average" by the western readers who are investigated [33]. Once again, compared with foreignization and ethics of difference, a new Cosmopolitanism translation ethics and a strategy of negotiation can effectively reveal and deal with both the moral equality and the tension in value pursuit of the two sides by looking at translation from both sides of the self and the other.

\section{Conclusion}

Foreignization and its ethics of difference inspire a worldwide concern about translator's invisibility, English cultural hegemony and translation's social role in the field of Translation Studies, however, they face an undeniable ethical dilemma of dualism and utilitarianism. Based on the new developments in Cosmopolitanism and Cosmopolitanism ethics and taking the fact that the selfother relationship in the translation of today's globalized world features mutual others and interpenetration, or a much more complicated and continuous interaction, a new Cosmopolitanism ethics and a strategy of negotiation are then put forward, according to which the ethical dilemma of foreignization and its ethics of difference are uncovered and an alternative is proposed through a comparison of Ezra Pound's and Yuanchong Xu's translation of classical Chinese poetry. Specifically, although foreignization morally treats the self and the other in translation as equal, it tends to replace the other's value pursuit with that of the self by either choosing certain aspects of the other's value pursuit which meet needs of the self's value pursuit as illustrated by Pound's case which largely ignores the other's foreignness, or imposing the self's value pursuit upon that of the other as illustrated by Xu's case which largely ignores the cultural context of the other. Hence, it may be drawn that a new Cosmopolitanism ethics and a strategy of negotiation provide a way out of the ethical dilemma of foreignization and its ethics of difference by revealing more complexity of the self-other relationship in translation and may enable translation practice to deal with self-other relationship more effectively, particularly in a world in which globalization deepens and in addition to conflicts, the self and the other penetrate each other much more than before.

\section{References}

[1] Liu, Yamen (2005). Venuit's Perspective on Translation Ethics and Its Self-Deconstruction. Chinese Translators Journal, 5: 40-45.

[2] Zhang, Jinhua (2009). Translation Ethics: An Investigation into Venuti's Translation Theory. Shanghai: Shanghai Jiaotong University Press, 165, 205, 192-193.

[3] Jiang, Tong (2012). The Genesis of Lawrence Venuti's Translation Theory: A Chain of Terms. Journal of Foreign Languages, 1: 54-61.

[4] Pym, Anthony (1996/2010). Venuti's Visibility. Target, revised edition, 8 (2): 165-177.

[5] Robinson, Douglas (1997a). What is translation?Centrifugal Theories, Critical Interventions. London: The Kent University Press, 97-112.

[6] Robinson, Douglas (1997b). Translation and Empire: Postcolonial Theory Explained. Manchester: St. Jerome, 109.

[7] Tymoczko, Maria (2000). Translation and political engagement. The Translator, 6 (1): 23-47.

[8] Gentzler, Edwin (2001). Contemporary Translation Theories (2nd edition). Clevedon, Buffalo, Toronto, Sydney: Multilingual Matters. Ltd., 36-43.

[9] Munday, Jeremy (2001). Introducing Translation Studies: Theories and Applications. London and New York: Routledge, $14,153,154$.

[10] Shamma, Tarek (2005). The Exotic Dimension of Foreignizing Strategies. The Translator, 11 (1): 51-67.

[11] Snell-Hornby, Mary (2006). The Turns of Translation Studies: New Paradigms or Shifting Viewpoints? Amsterdam/Philadelphia: John Benjamins Publishing Company, 145-148.

[12] Zhou, Xuanfeng (2018). Deconstruction and Reconstruction of "Ethics of Difference" from a Cosmopolitanism Perspective. Contemporary Literary Criticism, 5: 164.

[13] Venuti, Lawrence (1995/2018). The Translator's Invisibility: A History of Translation. New York: Routledge, xiii, viii-xvi, 164-178.

[14] Liu, Qing (2015). Reimagining the Global: From "Tianxia" to New Cosmopolitanism. Academic Monthly, 8: 5-15.

[15] Li, Jianhua and Zhang, Yongyi (2010). On the Core Propositions of Cosmopolitanism Ethics. Philosophical Trends, 5: 55-60.

[16] Zhang, Yongyi and Zhan, Mingzhang (2012). The Philosophical Bases of Cosmopolitanism Ethics. Theoretical Exploration, 4: 41-44.

[17] Fang, Wei (2013). "Translation Ethics" or "Studies of Norms"? Some Tentative Reflections on the Norms-oriented Studies of Translation Ethics at Home. Foreign Languages Research, 4: 70-75, 112.

[18] Dang, Lili (2006). Purposeful Selection of Translation Strategy-A Comparative Study of Xu Yuanchong's and Ezra Pound's Translation Strategies in Their Classical Chinese Poetry Translation. Northwest Normal University, 24-25, 50. 
[19] Pound, Ezra (1968). Literary Essays of Ezra Pound. Edited with an Introduction by T. S. Eliot. New York: New Directions Publishing Corporation, 6th printing: 25.

[20] Zhou, Jianxin (2012). A Probe into Ezra Pound's Concept of "Three Kinds of Poetry". Foreign Language Education, 1: 90.

[21] Pound, Ezra (2003). Ezra Pound: Poems and Translations. New York: Literary Classics of the United States, Inc., 257, $249,250,258$.

[22] Xu, Yuanchong (2013), 300 Tang Poems. Beijing: Dolphin Books, 44, 65.

[23] Yip, William (1969). Ezra Pound's Cathay. Princeton, New Jersey: Princeton University, 22, 145, 136, 143.

[24] Xu, Yuanchong (1984), An Art of Translation. Beijing: China International Translation and Publishing Corporation, iii, 60, 100.

[25] Zhu, Chaowei (2005). Construction and Reflection: A Study of Ezra Pound's Translation Theory. Shanghai: Shanghai Translation Publishing House, 220-222.

[26] Xu, Yuanchong (2013). Book of Poetry. Beijing: Dolphin Books, 189.
[27] Xu, Yuanchong (2013). Golden Treasure of Chinese Poetry in Han, Wei and Six Dynasties. Beijing: Dolphin Books, 61.

[28] Kenner, Hugh (1972). The Pound Era. London: Faber and Faber, 194.

[29] Yuan, Xingpei (1998). A Study of the Art of Chinese Poetry. Beijing: Peking University Press, 56, 60, 61, 95.

[30] Xu, Yuanchong (2014), Selected Poems of Li Bai. Beijing: China Translation Corporation, 146.

[31] Jiang, Hongxin (2014). A Study of Ezra Pound. Shanghai: Shanghai Foreign Language Education Press, 163, 276.

[32] Wang, Zhuo and Li, Quanwen (2010). A History of American Literature. Wuhan: Central China Normal University Press, 395.

[33] Ma, Hongjun (2006). From Literature Translation to Translated literature: A Study of Xu Yuanchong's Translation Theory and Practice. Shanghai: Shanghai Translation Publishing House, 207. 